ORIGINAL ARTICLE

\title{
Deep vein thrombosis after total hip and knee arthroplasty in Indian patients
}

\author{
V Jain, B K Dhaon, A Jaiswal, V Nigam, J Singla
}

Postgrad Med J 2004;80:729-731. doi: 10.1136/pgmj.2003.018127

See end of article for authors' affiliations ......................

Correspondence to: Dr V Jain, House No 194, Sector 21-C, Faridabad, Haryana, Pin 121001,

India; vineet_leo@ indiatimes.com

Submitted

23 December 2003

Accepted

23 February 2004
Background: Deep vein thrombosis (DVT) is one of the most common complications of total hip (THA) and total knee arthroplasty (TKA). Though the reported incidence of DVT is very high, that of proximal DVT is low and that of fatal thromboembolism is very low. Hence the issue of prophylaxis for DVT remains controversial.

The incidence of DVT is based on various studies in European and American populations. The Asian population is genetically and socially quite different from American and European populations, and the incidence of DVT can be quite different. Therefore a prospective study was initiated at our centre to determine incidence of DVT after THA and TKA in Indian patients.

Methods: A prospective study was conducted on 60 hips in 45 patients and 46 knees in 26 patients who underwent THA and TKA respectively, without any known risk factors for thromboembolic disease. DVT was studied by preoperative and postoperative serial colour Doppler ultrasonography. No prophylaxis was given to any of the patients.

Results: DVT was found in two patients who had undergone THA. No case of DVT was detected in any patient who had undergone TKA.

Conclusion: These results suggest that the incidence of DVT in Indian patients is very low and is not comparable with American and European populations. It is therefore not cost effective to advise prophylaxis in Indian patients undergoing THA/TKA who have no known risk factors for DVT.
$\mathrm{T}$ otal hip arthroplasty (THA) and total knee arthroplasty (TKA) have become standard treatments for patients exhibiting osteoarthritis of hip and knee from a number of causes, even in developing countries.

Deep vein thrombosis (DVT) is considered to be one of the most significant complications after THA and TKA. The significance of DVT lies in the possibility of pulmonary thromboembolism and occurrence of chronic venous insufficiency at a later stage.

The triad of venous stasis, hypercoagulability, and endothelial injury is associated with thrombus formation. The reported incidence of DVT after TKA and THA without prophylaxis is $40 \%-84 \%^{1}$ and $40 \%-70 \%,{ }^{2}{ }^{3}$ proximal DVT $8 \%-24 \%{ }^{1}$ and $10 \%-20 \%,{ }^{2}$ clinical DVT $7 \%-11 \%$ and $1 \%-3 \%,{ }^{2}$ non-fatal symptomatic pulmonary thromboembolism $1.2 \%-3 \%$ and $1 \%-2 \%,{ }^{2}$ and fatal pulmonary thromboembolism $0.1 \%-1.1 \%$ and $0.1 \%-1 \%$ respectively. ${ }^{4-6}$

Though incidence of DVT is very high, that of proximal DVT is low and that of fatal thromboembolism is extremely low. ${ }^{26}$ Concerns have also been expressed regarding efficacy and side effects of various methods used for prophylaxis. These have made the issue of prophylaxis for DVT controversial.

Though DVT resolves spontaneously, proximal DVT is more likely to result in a pulmonary thromboembolism compared with calf thrombi (distal thrombosis) without prophylaxis. ${ }^{7}$ Patients undergoing THA and TKA are considered at high risk, requiring prophylaxis..$^{8-10}$

Among various modalities used for diagnosis of DVT, Doppler ultrasonography has the advantage of being noninvasive, cost effective, can be repeated when required, has no side effects, and matches venography in sensitivity and specificity as far as proximal DVT is concerned. ${ }^{11}$

The reported incidence of DVT is based on various studies in European and American populations. The Asian population is genetically and socially quite different from American and European populations, and the incidence of DVT can also be different. ${ }^{12}$

Therefore we initiated a prospective study at our centre to determine the incidence of DVT after THA and TKA in Indian patients who had no known risk factors for thromboembolic disease. Serial colour Doppler ultrasonography was used to diagnose DVT.

\section{PATIENTS AND METHODS}

A prospective study including 60 hips in 45 patients and 46 knees in 26 patients undergoing THA and TKA, respectively, was conducted at our institute between November 2001 and November 2003. All patients gave informed consent.

Patients with a previous history of DVT, chronic venous insufficiency, stroke, varicose veins, large malignancy, renal insufficiency, recent myocardial infarction, heart failure, who were taking oral contraceptives, or on steroidal/hormonal/ anticoagulant drugs for any medical condition, were excluded from the study.

Preoperative assessment for DVT was done in all patients on both the lower limbs by colour Doppler ultrasonography, using an ATL 5000 HDI machine. Assessment included examination of bilateral common femoral, superficial femoral, popliteal, anterior tibial, and posterior tibial veins. They were assessed for flow, visualised thrombus, compressibility, and augmentation. A diagnosis of DVT was made where there was visualisation of thrombosis, absence of flow, lack of compressibility, or lack of augmentation.

All the patients for THA were operated on using the lateral approach. Patients were daily assessed for any signs of DVT. Patients were not given any prophylaxis for DVT during the study period.

Abbreviations: DVT, deep vein thrombosis; THA, total hip arthroplasty; TKA, total knee arthroplasty 
As in the preoperative period, assessment for postoperative DVT was done by colour Doppler ultrasonography on postoperative days $4( \pm 1)$ and $13( \pm 1)$ day. The same radiologist, who was very experienced in colour Doppler ultrasonography, repeated the study in all cases.

\section{RESULTS}

The average age of patients undergoing THA was 47 years and for TKA it was 65 years (table 1). The most common diagnosis in patients undergoing THA was avascular necrosis and in TKA it was primary osteoarthritis (table 2).

Hybrid THA was the commonest procedure done in patients undergoing arthroscopy of the hip. Combined spinal and epidural anaesthesia was given in 56 patients; the remaining patients were given general anaesthesia.

Proximal DVT was found in two patients; there was no case of distal DVT. One of these patients was a 59 year old woman, who had undergone a hybrid THA for avascular necrosis of her hip. She developed swelling of the right lower limb on the fourth postoperative day and proximal DVT was detected on colour Doppler ultrasonography. The other patient was a 62 year old woman who had undergone a cemented THA for fractured neck of femur. Proximal DVT was detected on the 14th postoperative day on Doppler ultrasonography.

Both the patients had no known risk factors and had not received any prophylaxis for DVT. Both were started on appropriate treatment for deep DVT, with subsequent resolution. There was no pulmonary thromboembolism in either of the patients. They were followed up for 15 months with no evidence of post-thrombotic symptoms.

DVT was detected preoperatively in one patient who had undergone hemiarthroplasty for fractured neck of femur seven years previously. It had become painful and the patient was referred for THA; this patient was excluded from the study.

No case of DVT was detected in any patient who had undergone TKA preoperatively or postoperatively in either the operated or the contralateral limb.

\section{DISCUSSION}

Both THA and TKA are a potent stimulus for thrombogenesis. While reviewing the studies on the incidence of DVT in Asian patients, we noted the paucity of material both in terms of number of patients studied and number of studies compared with patients and studies reported in the Western literature.

The study by Kim et al detected DVT in 10\% of 146 Korean patients undergoing cementless THA. ${ }^{13}$ Atichartakaran et al did not find any cases of DVT in a study of 19 Thai patients undergoing THA. ${ }^{12}$ Dhillon et al did a study on a multiethnic population undergoing THA and TKA in Malaysia. ${ }^{14}$ They detected DVT in $64.3 \%$ of 14 patients undergoing THA and in $76.5 \%$ of 34 those undergoing TKA. Fujita et al detected DVT in $22.6 \%$ of 164 patients undergoing THA and in $48.6 \%$ of 138 patients undergoing TKA. ${ }^{15}$ Ko et al reported DVT in four out of 22 cases of THA and 18 out of 58 cases of TKA in Chinese patients. ${ }^{16}$ Sudo et al detected DVT in $9.1 \%$ of 33 patients undergoing THA and in $4 \%$ of 25 patients undergoing TKA. ${ }^{17}$

Table 1 Clinical data of patients undergoing total hip arthroplasty (THA) and total knee arthroplasty (TKA)

\begin{tabular}{llllll}
\hline & Males & Females & Mean age & $\begin{array}{l}\text { No of bilateral } \\
\text { cases }\end{array}$ & DVT \\
\hline THA $(n=60)$ & 20 & 25 & 47 & 15 & 2 \\
TKA $(n=46)$ & 15 & 11 & 65 & 20 & 0 \\
\hline
\end{tabular}

\begin{tabular}{ll}
\hline $\begin{array}{l}\text { Table } 2 \\
\text { Dip arthroplasty (THA) and total knee }\end{array}$ \\
arthroplasty (TKA) \\
\hline Diagnosis & No (\%) of cases \\
\hline THA & $20(44.4)$ \\
Avascular necrosis & $15(33.3)$ \\
Ankylosing spondylitis & $10(22.2)$ \\
Fracture neck of femur & $20(76.9)$ \\
TKA & $6(23.1)$ \\
Osteoarthritis & \\
Rheumatoid arthritis & \\
\hline
\end{tabular}

During our study proximal DVT was found in only two cases of THA, and no case was found in patients undergoing TKA. As thrombogenesis is a complex process, it is difficult to explain the difference in our findings and those reported in the Western literature. They may be attributed to the genetic differences between the populations as well as differences in diet and lifestyle. ${ }^{12}$ Recently, factor $\mathrm{V}$ Leiden has been postulated as a risk factor for thrombosis. The relative risk of thrombosis in patients with factor $\mathrm{V}$ Leiden has been shown to be more than 10 times greater than for those with a deficiency of protein C, protein S, or antithrombin III. ${ }^{18}$ It was found in $5.27 \%$ of white people compared with $0.45 \%$ of Asians during the screening of 4047 people in the United States. ${ }^{19}$ This difference in prevalence of factor V Leiden may be responsible for difference in incidence of DVT.

Old age is a risk factor for DVT ${ }^{20}$; in our study the average age was 47 years in THA and 65 years in TKA. The two patients who developed DVT after THA were 59 and 62 years respectively. Cemented femoral implant has been found to enhance coagulation ${ }^{21}$; however, it was used in 26 hips yet DVT was detected in only two cases.

The risk of DVT exists until three months after surgery and in $20 \%$ of cases DVT also develops in the contralateral limb. ${ }^{22}$ Therefore, risk of development of DVT is increased when the limb on the opposite side is operated on later. Though there were 15 cases of bilateral THA in patients where the contralateral side was operated on after a gap of three weeks, there were no cases of DVT.

In cases of bilateral simultaneous TKA, Stulberg et al reported DVT in $73.6 \%$ of their patients, ${ }^{23}$ and Dhillon et al reported DVT in all six patients who underwent bilateral TKA. ${ }^{14}$ In our series there were 14 cases of bilateral simultaneous TKA, and six cases of bilateral sequential TKA, but there were no cases of DVT.

Preoperative Doppler ultrasonography prevents any false positive cases, as well as forewarns the surgeon regarding the increased risk of DVT and need for prophylaxis. It revealed DVT in one patient who had undergone hemiarthroplasty previously. Therefore, it is prudent to do preoperative Doppler ultrasonography to detect any pre-existing DVT, especially in patients who are undergoing a repeat procedure on the same or the contralateral joint.

Though our study group was small, our results suggest that incidence of DVT in Indian patients is very low and is not comparable with American and European populations.

These findings are relevant in today's world of globalisation and also for other South East Asian countries that share a common genetic pool and socioeconomic conditions. There is often restricted government funding, with emphasis on providing basic essential treatment to the maximum number of people. In view of this, and in an era of evidence based medicine, it is not cost effective to advise prophylaxis in patients undergoing THA and TKA who have no known risk factors for DVT. 


\section{ACKNOWLEDGEMENT}

The authors would like to acknowledge the role of the Department of Radiodiagnosis, L N Hospital in the conduct of this study.

\section{Authors' affiliations}

V Jain, B K Dhaon, A Jaiswal, V Nigam, J Singla, Department of Orthopaedics and Radiodiagnosis, L N Hospital, New Delhi, India

\section{REFERENCES}

1 Westrich GH, Haas SB, Mosca P, et al. Metaanalysis of thromboembolic prophylaxis after total knee arthroplasty. J Bone Joint Surg Br 2000;82:795-800.

2 Gillespie W, Murray D, Gregg PJ, et al. Risks and benefits of prophylaxis against venous thromboembolism in orthopaedic surgery. J Bone Joint Surg Br 2000:82:475-9.

3 Imperiale TF, Speroff T. A meta-analysis of methods to prevent venous thromboembolism following total hip replacement. JAMA 1994;271:1780-5.

4 Amstutz HC, Dorey FJ. Are recommendations for the routine use of thromboprophylaxis in total hip arthroplasty justified. J Bone Joint Surg Br 2000:82:473-4.

5 Thomas DP. Prophylaxis against deep vein thrombosis after total hip replacement. J Bone Joint Surg Br 2000;82:469-72.

6 Prentice CRM. Thromboprophylaxis - which treatment for which patient. $J$ Bone Joint Surg Br 2000;82:483-5.

7 Lieberman JR. Prevention of deep venous thrombosis following primary and revision hip and knee arthroplasty. In: Callaghan JJ, Rosenburg AG, Rubash HE, eds. The adult hip. Philadelphia, PA: Lippincott Raven, 1998: chapter 55 .

8 THRIFT Consensus Group. Risk of and prophylaxis for venous thromboembolism in hospital patients. BMJ 1992;305:567-73

9 National Institutes of Health Consensus Development. Prevention of venous thrombosis and pulmonary embolism. JAMA 1986;256:744-9.
10 Geerts WH Heit JA Clagett GP et al Prevention of venous thromboembolism. Chest 2001; 1 19:132S-75.

11 Grady-Benson JC, Oishi CS, Colwell CW Jr, et al. Postoperative surveillance for deep venous thrombosis with duplex ultrasonography after total knee arthroplasty. J Bone Joint Surg Am 1994;76:1649-56.

12 Atichartakaran V, Pathepchotiwong K, Kerochana S, et al. Deep vein thrombosis after hip surgery among Thai. Arch Intern Med 1988; 148:1349-53.

$13 \mathrm{Kim}$ YH, Suh JS. Low incidence of deep vein thrombosis after cementless total hip arthroplasty. J Bone Joint Surg Am 1988;70:878-82.

14 Dhillon KS, Askander A, Doraisamy S. Postoperative deep vein thrombosis in Asian patients is not a rarity. J Bone Joint Surg $\mathrm{Br}$ 1996;78:427-430

15 Fujita S, Hirota S, Oda T, et al. Deep vein thrombosis after total hip or total knee arthroplasty in patients in Japan. Clin Orthop 2000;375:168-74.

16 Ko PS, Chan WF, Siu TH, et al. Duplex ultrasonography after total hip or knee arthroplasty. Int Orthop 2003;27:168-71.

17 Sudo A, Sano T, Horikawa K, et al. The incidence of deep vein thrombosis after total hip and knee arthroplasties in Japanese patients: a prospective study. J Orthop Surg 2003;11:174-7.

18 Bertina RM, Koeleman BP, Koster T, et al. Mutation in blood coagulation factor $\mathrm{V}$ associated with resistance to activated protein $\mathrm{C}$. Nature 1994;369:64-7.

19 Ridker PM, Miletich JP, Hennekens $\mathrm{CH}$, et al. Ethnic distribution of factor $\mathrm{V}$ Leiden in 4047 men and women. JAMA 1997;277:1305-7.

20 Sikorski JM, Hampson WG, Staddon G. The natural history and aetiology of deep vein thrombosis after total hip replacement. J Bone Joint Surg $\mathrm{Br}$ $1981 ; 63: 171-7$

21 Sharrock NE, Go G, Harpel PC, et al. Thrombogenesis during total hip arthroplasty. Clin Orthop 1995;319:16-27.

22 Warwick D, William MH, Bannister GC. Death and thromboembolic disease after total hip replacement. J Bone Joint Surg $\mathrm{Br}$ 1995;77:6-10.

23 Stulberg BN, Insall JN, Williams GW, Ghelman B. Deep vein thrombosis following total knee replacement. J Bone Joint Surg Am 1984;66:194-201. 